\title{
Primary palliative Care in General Practice - Dorsmak study protocol of a three-stage mixed- methods organizational health services research study
}

Helen Ewertowski ${ }^{1 *+}$, Fabian Tetzlaff $^{1 \dagger}$, Stephanie Stiel ${ }^{1}$, Nils Schneider ${ }^{1}$ and Saskia Jünger ${ }^{1,2}$

\begin{abstract}
Background: The focus of this project is on improving the provision of primary palliative care (PC) by general practitioners (GPs). While approximately 10-15\% of the incurable, seriously ill or dying people will be in need of specialist PC, the vast majority can be adequately treated within generalist care. The strengthening of the GP's role in PC, as well as ensuring close collaboration between specialist PC services and GPs have been identified as top priorities for the improvement of PC in Germany. Despite healthcare policy actions, diverse obstacles still exist to successful implementation of primary PC on a structural, process, and economic level. Therefore, this project aims at addressing barriers and facilitators to primary PC delivery in general practice in Germany.
\end{abstract}

Methods: The study follows a three-step approach; first, it aims at systematically analyzing barriers and facilitators to primary PC provision by GPs. Second, based on these outcomes, a tailored intervention package will be developed to enhance the provision of primary PC by GPs. Third, the intervention package will be implemented and evaluated in practice. The expected outcome will be an evidence-based model for successful implementation of primary PC delivery tailored to the German healthcare system, followed by a strategic action plan on how to improve current practice both on a local level and nationally.

Discussion: The first step of the project has been partly completed at the time of writing. The chosen methodologies of four sub-projects within this first step have opened up different advantages and disadvantages for the data collection. In sum of all sub-projects, the different methodologies and target groups contributed valuable information to the systematic analysis of barriers and facilitators to primary PC provision by GPs.

Trial registration: The study (BMBF-FK 01 GY 1610) was retrospectively registered at the German Clinical Trials Register (Deutsches Register Klinischer Studien) (Registration No DRKS00011821; date of registration: December 04th 2017) and at the German Register of health care research (Versorgungsforschung Deutschland - Datenbank) (Registration $N^{\circ}$ VfD_ $^{-}$ ALLPRAX_16_003817; date of registration: March 30th 2017).

Keywords: Primary palliative care, General practice, Organizational health services research, Complex intervention

\footnotetext{
* Correspondence: Ewertowski.Helen@MH-Hannover.de

${ }^{\dagger}$ Equal contributors

${ }^{1}$ Institute for General Practice, Hannover Medical School, Carl-Neuberg-Straße

1, 30625 Hanover, Germany

Full list of author information is available at the end of the article
} 


\section{Background}

In Germany, as in many other high-income countries, it is anticipated that both the proportion and the actual numbers of people who should receive palliative care (PC) is increasing considerably [1-3]. The remit of PC has expanded since its relevance for other diseases than cancer has been widely acknowledged; in addition, integration of PC at an earlier stage in the disease process not only close to death - has been shown to be beneficial [2]. In addition, the demand in primary care will rise with an ageing population and changing patterns of mortality - people at older ages often suffer from multiple chronic diseases of indeterminate prognosis [4]. According to estimates by the German Association for Palliative Medicine (DGP), up to $90 \%$ of the approximately 850,000 people who die in Germany each year will be in need of PC [3]. Of those, about $10 \%$ will require specialist $\mathrm{PC}$ at some point, while the majority will need primary PC. It is estimated that general practitioners (GPs) on average care for 3-4 patients with PC needs per quarter; however, these figures presumably underestimate the real care extent since these estimates do not appropriately reflect care for patients with nononcological conditions [5]. The situation of patients in need of $\mathrm{PC}$ in a general practice is characterized by multi-morbid patients with a broad spectrum of conditions and a predominance of non-oncological chronic diseases such as cardiovascular or pulmonary diseases [6]. From a public health perspective, these trends demand for new approaches to service delivery; research into models for successful implementation of primary $\mathrm{PC}$ is therefore paramount.

\section{International evidence base regarding primary palliative care}

Primary PC can be defined as "the clinical management and care coordination including assessment, triage, and referral using a palliative approach for patients with uncomplicated needs associated with a life limiting illness and/or end of life care. Has formal links with a specialist palliative care provider for purposes of referral, consultation and access to specialist care as necessary" [7]. Evidence from international research consistently underlines the importance of PC in a generalist setting as an indispensable element in the continuum of care provision, as well as the pivotal role of the GP in the provision of primary PC $[8,9]$. In a number of countries, the fundamental right for patients of all diagnoses to receive $\mathrm{PC}$ from an early point in the course of a life-limiting condition is now anchored in policy and legislation, involving an increased emphasis upon the role of primary PC [2]. It has been argued that a wise combination of generalist and specialist PC constitutes a more sustainable and cost-effective approach to care provision [10]. Accordingly, in the past decade, important scientific, policy and advocacy initiatives were developed internationally to facilitate primary $\mathrm{PC}$ provision by GPs and to support their endeavors [11-14].

\section{Challenges related to the provision of primary palliative care in general practice}

Despite the widely acknowledged importance of GPs' engagement in primary PC [11], a number of - partly interrelated - challenges were identified related to the delivery of primary PC in practice; these concern 1) structural barriers (e.g. GP undersupply and uneven distribution in rural versus urban areas), knowledge barriers (e.g. lack of knowledge, skills, and clinical routine in providing $\mathrm{PC}$; practical obstacles to undertake training), 2) service barriers (e.g. lack of active GP involvement in transition from curative to PC), and 3) consequences of the "specialization" of PC (e.g. unclear role definitions and lack of clarity regarding roles and responsibilities of generalist PC and communication and collaboration between generalist and specialist care providers) $[2,15]$.

\section{German context}

Position papers and professional guidelines by leading authorities [16, 17], as well as nationwide consented public health actions to improve PC provision in Germany [18], define generalist PC as the foundation of all $\mathrm{PC}$ concepts and emphasize the pivotal role of the GP in PC delivery. Research confirmed that GPs in Germany regard it as their responsibility and as part of their professional self-perception to care for their patients throughout the whole disease trajectory, including provision of end-of-life care. The crucial importance of strengthening PC by GPs was even anchored in the 'hospice and palliative care law' passed in 2015 [19]. However, to date it has not been clearly defined what PC in general practice exactly entails [20]. The clinical guideline for PC for cancer patients [16] details generalist PC as follows: palliative basis and follow-up assessment of the patient's status; the treatment of symptoms of low to medium complexity; involvement of specialist PC if appropriate; and identification of treatment goals in agreement with the patient. The ideal situation described in the law and in the clinical guideline is, however, far from being implemented into practice, and a pronounced undersupply of patients with generalist PC has been stated [3]. Routine data of health insurances indicate that primary PC occurs too late in the course of a life-limiting disease, and predominantly for patients with oncological diseases, confirming the still prevailing idea among GPs that PC is primarily applicable close to a patient's death and in the context of cancer care [3]. Until now, the regulatory framework for primary PC delivered by GPs merely consists of four specific billing codes introduced in the medical compensation system in 2013, while not 
allowing for statements regarding the quality of the care provided. In addition, the codes only refer to single services by GPs, while nursing and other care is not included. This is critically discussed since these billing codes do not ensure essential features of holistic PC provision such as coordination, network structures, and multi-professional care. Particularly the team approach, a key element of successful and sustainable PC provision, is not adequately considered in the current regulations for primary care. Unlike with specialist palliative home care, where conditions, admission criteria, and care activities have been defined, for generalist palliative care this is very vague, bearing confusion and uncertainties for professionals, patients and families, as well as other involved stakeholders [20]. The intent to strengthen primary PC economically by improving remuneration for services delivered by primary care providers was recently anchored in law [19]. However, until now, no systematic approaches for the practical implementation of these innovations are in place, and empirical evidence on costs and benefits of respective care models is lacking.

GPs providing PC in Germany are confronted with the difficulty of integrating the demands of end of life care with a generalist caseload that usually implies many competing priorities $[2,21,22]$. In international comparison, physicians in Germany showed the highest selfassessed workload and the greatest number of patient contacts, with at the same time the shortest time per patient contact of only $9.1 \mathrm{~min}$ [23]. There is a tension between a pressurized context of care [2] and the nature of PC work with its unpredictable demands, uncertainty of illness trajectory, and its difficulty in planning, its intensiveness, and its personal strains [21]. Interactions with patients in the context of $\mathrm{PC}$ provision tend to require high investment of time, communicative and emotional effort, and tolerance towards uncertain outcomes. These requirements can become incompatible with the other demands on a GP in his or her every day practice [24]. For example, frequent and time-consuming home visits may be difficult to cope with in a regular every day practice characterized by high workload and time pressure. In addition, depending on the regional or local care infrastructure, GPs often feel as "lone fighters" in providing $\mathrm{PC}$ for their patients, while team composition and access to specialist support were emphasized as crucial for the capacity to provide $\mathrm{PC}$ in a generalist setting [22].

In summary, a first foundation of research [6, 24], education and professional guidance [16, 25], and policy initiatives $[17,19]$ has been laid for enhancing primary PC delivery in Germany. However, the scientific evidence base and the conceptual development are not as far advanced as in countries such as the UK, the Netherlands, or Australia. To date, a comprehensive program for enhancing primary PC has not been developed. Although core findings and recommendations from other countries may be partly transferrable, the concrete practice largely depends on the particular conditions of the national healthcare system and structural prerequisites in the regional context of healthcare provision, with implications for the role and responsibility of the GP in the provision of care.

\section{Aim and research question}

This research project aims at providing an empirical basis for the sustainable implementation of primary PC by GPs. Sub-goals are:

(a) the systematic analysis of barriers and facilitators to primary PC provision using a theoretical framework from implementation science,

(b)the development of a tailored intervention package to enhance primary PC provision and support care providers to integrate the new processes with their everyday practice, and

(c) the implementation and evaluation of the intervention package to assess its practical applicability and its effects on patient care.

\section{Research questions}

I. Analysis and operationalization of barriers to primary PC provision by GPs in the German healthcare context on a structural, educational, process, and economic level: Which mechanisms and formal regulations impede routine embedding of PC provision in GPs everyday clinical practice at individual and collective level?

II. Identification and operationalization of concrete measurable actions to improve the implementation of primary PC delivery by GPs: Which measures will have the potential to facilitate integration of end of life care with a generalist caseload and to enable the GP and his practice team to provide high quality PC to their patients? Which measures will be suitable to promote collaboration with other care providers relevant for PC delivery?

III.Testing and evaluation of a tailored intervention package for the facilitation of primary PC delivery by GPs in Germany: What is its practicality, as well as its impact on care and patient-relevant outcomes? How well does it score compared to other models of GP involvement in PC delivery?

\section{Methods and design}

To ensure scientific quality and rigor, the study design was developed in line with the recommendations for 
organizational health services research and theoretical foundation of health services research by the German Network for Health Services Research [26, 27]. The study encompasses three phases modelled after the framework for the development and evaluation of tailored interventions by Campbell et al. [26] (Fig. 1).

a) The theoretical phase of this research is designed to gain an in-depth understanding of the mechanisms that determine the (un)successful delivery of primary PC in general practice.

b) The modelling phase uses participatory methods and consensus building techniques in order to ensure ownership of the resulting intervention package and hereby enhance advocacy, dissemination, and the likelihood that the intervention will be successfully implemented into practice on the long term.

c) The implementation and evaluation phase is designed to test and evaluate the acceptance, feasibility, and applicability of the intervention package in practice. Using formative evaluation, it will be examined how the individuals and groups involved in the delivery of primary PC engage in the mobilization of resources to secure consent, trust, and cooperation, as well as in the realization of activities that may lead to routine incorporation of elements of practice into everyday work. Summative evaluation will be employed to assess the outcomes in terms of the quality of patient care, the costs and benefits for the involved stakeholders, and the
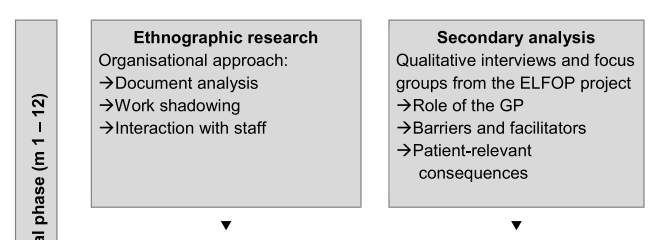

Insights into practices involved in the delivery of primary PC in

general practice

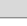
facilitators of primary $P C$ provision by GPs

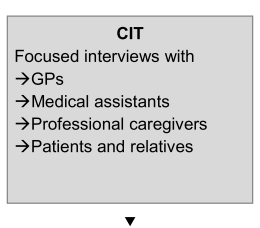

$\checkmark$

\section{Focused insights into} determinants of excellent practice vs. undesirable or harmful events

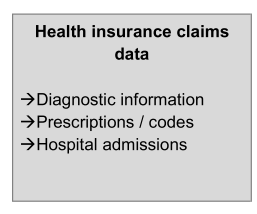

$\checkmark$

Morbidity of patients

Service usage Prescriptions Patient-relevant outcomes

v

Expected outcome: programme theory on determinants of primary PC by GPs

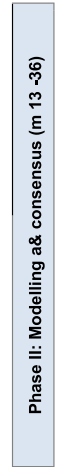

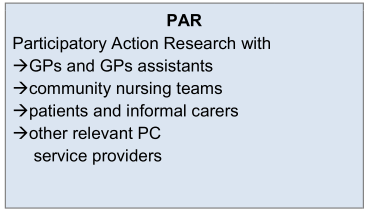

Set of service development statements as guidance for the development of a tailored intervention package

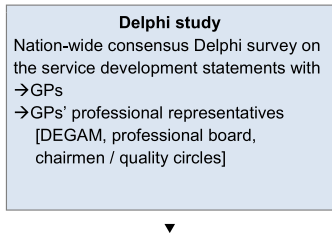

$\checkmark$

Nationally consented set of service development statements that will inform a strategic action plan on how to enhance $\mathrm{PC}$ provision by GPS $\checkmark$

Expected outcome: intervention package tailored to the German healthcare context

Formative evaluation Formative evaluation
Formative evaluation of the tailored intervention package: $\rightarrow$ Organisational ethnographic approach including individual and group interviews with relevant stakeholders $\rightarrow$ Assessment of two exemplary other regions in Germany $\rightarrow$ Assessment of two exemplary other regions in Germany

$$
\checkmark
$$

Structural and process features of the intervention package: $\rightarrow$ Feasibility and acceptance in practice $\rightarrow$ Comparison of its usefulness with other approaches to general / specialist PC provision (different contracts with health insurance funds, different roles of GPs in the local delivery of PC)

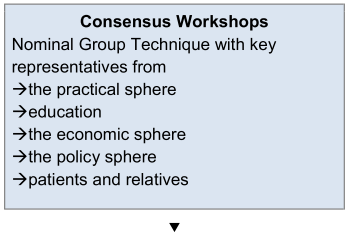

Consensus on the feasibility and effectiveness of the proposed strategies and a working model for their
anplativents implementation into practice

Fig. 1 Design of the research project, modelled after Campbell et al. [26, 27] 
impact of the intervention package for the healthcare system.

\section{Study population and data collection}

Phase I - Theoretical Phase: The theoretical phase comprises four sub-projects.

First, an organizational ethnographic field approach will be applied to gain insights into the practices involved in delivering primary PC and to analyze barriers and facilitators. Data will be collected by means of document analysis (such as care plans, case notes, registers); by work shadowing (observation of daily routines, team meetings, staff interactions, home visits); and by interaction with staff (informal interviews, cognitive interviewing / think-aloud technique) [28]. Field notes will be taken according to a pre-defined scheme [29] and will be transformed into accounts including information about procedures, observations of actions and interactions, quotations of conversations, interpretations (e.g. of underlying attitudes), and the researcher's intuitive thoughts and memos. These accounts will be imported into data files using software for qualitative text analysis (MaxQDA ${ }^{\circ}$ ).

Second, a secondary analysis of qualitative data [30] will be undertaken with a particular focus on barriers and facilitators of PC provision by GPs. Data are available from a recently concluded project on end of life care for frail older patients in family practice (ELFOP), a longitudinal study on needs, appropriateness and utilization of services (funding number: BMBF-FK 01 GY 1120) funded by the Federal Ministry of Education and Research. Participants were selected through theoretical sampling to include GPs with different backgrounds, working conditions (single or joint practice), and working in rural and urban areas characterized by diverse care infrastructures. Both the interviews and the group discussion include relevant information on the GPs' perception of tasks, problems, challenges in the end-of-life care for frail older people, as well as on their perceived roles, responsibilities, and professional selfperception within this context of care.

Third, based on the findings from ethnographic research and secondary interview analysis focused interviews will be conducted with GPs, GP assistants or nurses from home care teams or inpatient service provider, patients, and their relatives (Table 1) using the Critical Incident Technique (CIT) [31, 32] to identify significant mechanisms that result in excellent practice versus in undesirable or even harmful events.

Fourth, secondary analysis of health insurance claims data of the AOK - Die Gesundheitskasse für Niedersachsen (AOKN, statutory health insurance) and BARMER (statutory health insurance), and from the GPs' office software will serve to describe the morbidity and service usage of patients, assess patient-relevant outcomes such as hospital admissions, estimate the time investment and costs for the provision of primary PC by GPs, and to draw inferences on the relevant laws, professional regulations, and reimbursement systems (see Table 2).

Phase II - Modelling Phase: The modelling phase consists of three sub-projects building up on each other.

First, Participatory Action Research (PAR) [33] will be undertaken with general practices, community nursing teams, patients and informal carers, as well as other relevant $\mathrm{PC}$ service providers to define adequate operationalization of PC processes and quality outcomes, and to condense a set of service development statements [34, 35].

Second, a nation-wide consensus Delphi study will be undertaken with GPs and their professional representatives such as the GPs' professional federation, the Medical Chamber, and the German association of general practice (DEGAM) to seek expert consensus on these service development statements.

Third, consensus workshops will be conducted in the follow-up of the Delphi study, using the Nominal Group Technique [36] to elaborate a strategic action plan on how to put the service development statements into practice. Workshop participants will be key representatives from the practical, education, economic, and policy sphere, as well as representatives of patients and relatives. Data collected during this phase will be integrated during analysis (see $[2,37]$ ) to design the tailored intervention package.

Finally, an intervention package will be developed for enhancing the integration of PC provision into general practice, drawing on the example of the Gold Standards Framework for Palliative Care [12], but adapting it to the German context. A participatory framework and consensus building techniques will be applied to promote ownership of the developed elements and to enhance commitment among the relevant stakeholders.

Phase III - Implementation and evaluation: The intervention package developed in phase II will be implemented and evaluated in an exemplary test region in Lower Saxony.

First, formative evaluation will use an organizational ethnographic approach including individual and group interviews with relevant stakeholders to (a) test the feasibility and acceptance of the intervention in practice, and (b) to compare the intervention to two exemplary other regions in Germany with different approaches to generalist and specialist PC provision in terms of contracts with health insurance funds, different roles of GPs in the local delivery of PC (e.g. Westphalia-Lippe).

Second, summative evaluation will be accomplished to assess the effects of the intervention on patient care in terms of physical, practical, and psychological outcomes. Data sources will be a questionnaire survey among the relevant stakeholders involved in PC provision; analysis of clinical and health insurance funds routine data to assess 
Table 1 Target/ study population detailed for each work package of data collection

\begin{tabular}{|c|c|c|c|}
\hline Work package & Target population & Proposed sample size & Sampling strategy \\
\hline Ethnographic research & $\begin{array}{l}\text { GPs; GPs assistants, professional } \\
\text { caregivers }\end{array}$ & $n=30$ & $\begin{array}{l}\text { The Institute of General Practice's education and } \\
\text { research network of } n=250 \text { general practices; } \\
\text { theoretical sampling contrasting: rural vs. urban; } \\
\text { single vs. joint practice; specific palliative education } \\
\text { vs. nonspecific palliative education }\end{array}$ \\
\hline Secondary analysis & $\begin{array}{l}\text { GPs, GPs assistants, professional } \\
\text { caregivers }\end{array}$ & $\begin{array}{l}\text { interviews: } \\
n=52 \\
\text { group discussions: } \\
n=3\end{array}$ & $\begin{array}{l}\text { Existing data set of interviews / one focus group } \\
\text { with GPs conducted within the ELFOP project; all } \\
\text { interviews and the focus group are included }\end{array}$ \\
\hline CIT & $\begin{array}{l}\text { GPs, GPs assistants, professional } \\
\text { caregivers, patients and relatives }\end{array}$ & $n=16$ & $\begin{array}{l}\text { Theoretical sampling contrasting: rural vs. urban; } \\
\text { diagnosis; single vs. joint practice; men vs. women }\end{array}$ \\
\hline $\begin{array}{l}\text { Analysis of Health insurance } \\
\text { claims data }\end{array}$ & $\begin{array}{l}\text { GPs' patients identified as being } \\
\text { in need of PC }\end{array}$ & not applicable & $\begin{array}{l}\text { Health insurance claims data: all AOKN and } \\
\text { BARMAR insured persons in Lower Saxony with } \\
\text { palliative billing codes }\end{array}$ \\
\hline PAR & $\begin{array}{l}\text { GPs, community nursing teams, } \\
\text { patients and informal carers, other } \\
\text { relevant PC providers }\end{array}$ & not applicable & Theory-based purposive sampling [55] \\
\hline Delphi study & $\begin{array}{l}\text { GPs' professional representatives } \\
\text { and other relevant experts for } \\
\text { health policy decision making } \\
\text { and healthcare planning }\end{array}$ & $n=30$ & $\begin{array}{l}\text { DEGAM; DGP; GPs' chairmen / quality circles; the } \\
\text { Institute of General Practice's close links with GPs' } \\
\text { professional boards and associations } \\
\text { (Hausärzteverband) }\end{array}$ \\
\hline Consensus workshops & $\begin{array}{l}\text { GPs' professional representatives; } \\
\text { health insurers; experts for medical } \\
\text { education; and other relevant } \\
\text { experts for health policy decision } \\
\text { making and healthcare planning }\end{array}$ & $n=20$ & $\begin{array}{l}\text { Two groups with approximately } 10 \text { participants } \\
\text { each; theory-based purposive sampling [55] }\end{array}$ \\
\hline $\begin{array}{l}\text { Implementation of the } \\
\text { intervention package }\end{array}$ & $\begin{array}{l}\text { GPs', community nursing teams, } \\
\text { health insurers; and other relevant } \\
\text { experts for health policy decision } \\
\text { making and healthcare planning }\end{array}$ & not applicable & $\begin{array}{l}\text { Exemplary test region in Germany (Lower Saxony) } \\
\text { involving } n=8 \text { general practices, as well as all } \\
\text { relevant service providers and stakeholders in the } \\
\text { respective region }\end{array}$ \\
\hline $\begin{array}{l}\text { Questionnaire survey } \\
\text { (Summative evaluation) }\end{array}$ & $\begin{array}{l}\text { GPs', community nursing teams, } \\
\text { health insurers; and other relevant } \\
\text { experts for health policy decision } \\
\text { making and healthcare planning }\end{array}$ & $n=130$ & $\begin{array}{l}\text { Service providers, insurers, and other local } \\
\text { stakeholders involved in the implementation } \\
\text { of the tailored intervention package (Phase II) } \\
\text { and from two exemplary other regions in Germany }\end{array}$ \\
\hline $\begin{array}{l}\text { Patient-relevant outcomes } \\
\text { (Summative evaluation) }\end{array}$ & Patients and informal carers & $\begin{array}{l}\text { standardized scales } \\
n=32 \\
\text { interviews } \\
n=16\end{array}$ & $\begin{array}{l}\text { Patients and informal carers attended by general } \\
\text { practices who are involved in the implementation } \\
\text { of the tailored intervention package (Phase II) and } \\
\text { from two exemplary other regions in Germany }\end{array}$ \\
\hline
\end{tabular}

the effects on patient care, service usage, and costs of care; and perceptions of patients and relatives regarding the outcomes of care using established instruments such as the Palliative Outcome Scale [38] (Table 2).

\section{Sample size calculation}

Phase I: For the ethnographic field research the participation of $N=8$ GPs, GP assistants and other medical professionals was planned considering methodological arguments of theoretical sampling when contrasting practices characteristics such as rural vs. urban, single vs. joint practice, men vs. women. At least $N=16$ interviews following the Critical Incident Technique were proposed which relates to the methodological experience that data saturation in qualitative analysis via Grounded Theory. Data collection will end once data saturation is obtained which will be the case when no more new or valuable information can be attained, further coding is no longer feasible, and once the study can be replicated [39]. This usually takes place after $12-15$ interviews. The sample size of secondary analysis of qualitative data from ELFOP is pre-determined due to the retrospective design of the sub project. The sample size of the secondary analysis of health insurance claims data is not applicable and will be defined by the amount of specific data sets of the current insured persons of the AOKN and BARMER.

Phase II: Reflecting the current literature on successful Delphi studies, $N=30$ participants who complete each Delphi round are planned. Due to the expected drop-out of $60 \%$ during the course of the Delphi assessment, probably three times as many participants will be initially invited to this sub project [18]. The final consensus workshops aims to include $N=20$ stakeholders following a theory-based purposive sampling [40]. 
Table 2 Outcomes, comparators, and data sources

\begin{tabular}{|c|c|c|}
\hline Outcome & Measure(s), indicator(s) & Data source \\
\hline \multicolumn{3}{|l|}{ Patient-related outcomes } \\
\hline Quality of life & $\begin{array}{l}\text { Physical and psychosocial wellbeing, social } \\
\text { support, financial strain }\end{array}$ & $\begin{array}{l}\text { Standardized quality of health / care related } \\
\text { measures such as POS }{ }^{\mathrm{a}} \text {; } \text { QODD }^{\mathrm{b}} ; \mathrm{QUELC}^{\mathrm{C}}\end{array}$ \\
\hline Quality of care & Unplanned hospital admissions & Health insurance claims data \\
\hline \multicolumn{3}{|l|}{ Service usage and time investment } \\
\hline Service usage & $\begin{array}{l}\text { GPs' consultations and home visits; } \\
\text { prescriptions (medication, medical aids, } \\
\text { interventions); referral to specialists and } \\
\text { other service providers; out-of-hours } \\
\text { contacts; emergency interventions }\end{array}$ & $\begin{array}{l}\text { Health insurance claims data } \\
\text { GP's office software }\end{array}$ \\
\hline GPs' time investment & $\begin{array}{l}\text { Time dedicated to assessments, home visits, } \\
\text { telephone consultations, physical care, and } \\
\text { psychosocial care }\end{array}$ & $\begin{array}{l}\text { Time registration (ethnographic } \\
\text { field research) }\end{array}$ \\
\hline \multicolumn{3}{|c|}{ Impact on GPs' and practice staff's ability and capacity to deliver primary palliative care } \\
\hline Quality of palliative care delivery & $\begin{array}{l}\text { GPs' and practice staff's appraisal of the } \\
\text { quality of PC provided to their patients }\end{array}$ & $\begin{array}{l}\text { Organizational ethnographic field research } \\
\text { including individual and group interviews }\end{array}$ \\
\hline Quality of care other than palliative care & $\begin{array}{l}\text { GPs' and practice staff's appraisal of the } \\
\text { quality of care provided to other patients }\end{array}$ & $\begin{array}{l}\text { Organizational ethnographic field research } \\
\text { including individual and group interviews }\end{array}$ \\
\hline Work satisfaction & $\begin{array}{l}\text { GPs' and practice staff's work-related } \\
\text { satisfaction and sense of meaningfulness }\end{array}$ & $\begin{array}{l}\text { Organizational ethnographic field research } \\
\text { including individual and group interviews }\end{array}$ \\
\hline \multicolumn{3}{|l|}{ Economic evaluation } \\
\hline Direct costs for the healthcare system & $\begin{array}{l}\text { Service usage (consultations and home } \\
\text { visits, prescriptions of medicines and } \\
\text { medical aids, specialist referrals, social } \\
\text { services, out-of-hours contacts, emergency } \\
\text { interventions) }\end{array}$ & $\begin{array}{l}\text { Health insurance claims data } \\
\text { GP's office software }\end{array}$ \\
\hline Direct costs for patients and relatives & $\begin{array}{l}\text { Additional costs for medications and } \\
\text { therapeutic interventions not covered } \\
\text { by the health insurance funds }\end{array}$ & $\begin{array}{l}\text { Organizational ethnographic field research } \\
\text { including individual and group interviews }\end{array}$ \\
\hline Indirect costs for patients and relatives & $\begin{array}{l}\text { Social isolation; (temporary) work loss; } \\
\text { abandon of activities or relationships }\end{array}$ & $\begin{array}{l}\text { Organizational ethnographic field research } \\
\text { including individual and group interviews }\end{array}$ \\
\hline $\begin{array}{l}\text { Direct costs for GPs and other healthcare } \\
\text { providers }\end{array}$ & $\begin{array}{l}\text { Costs invested for } \mathrm{PC} \text { not remunerated } \\
\text { within the medical compensation system }\end{array}$ & $\begin{array}{l}\text { Organizational ethnographic field research } \\
\text { including individual and group interviews }\end{array}$ \\
\hline $\begin{array}{l}\text { Indirect costs for GPs and other } \\
\text { healthcare providers }\end{array}$ & $\begin{array}{l}\text { Personal strain; impact on healthcare } \\
\text { professionals' private lives; abandon of } \\
\text { activities or relationships }\end{array}$ & $\begin{array}{l}\text { Organizational ethnographic field research } \\
\text { including individual and group interviews }\end{array}$ \\
\hline \multicolumn{3}{|l|}{ Feasibility of the intervention package } \\
\hline $\begin{array}{l}\text { Process monitoring and formative } \\
\text { evaluation of the implementation phase }\end{array}$ & $\begin{array}{l}\text { Normalization Process Theory core } \\
\text { constructs (coherence, cognitive } \\
\text { participation, collective action, and reflexive } \\
\text { monitoring) }\end{array}$ & $\begin{array}{l}\text { NoMADd assessment instrument for the } \\
\text { evaluation of the implementation of } \\
\text { complex interventions }\end{array}$ \\
\hline
\end{tabular}

${ }^{\text {a Palliative Outcome Scale [38] }}$

${ }^{\mathrm{b}}$ Quality of Dying and Death questionnaire [47]

cQuality of End of Life Care Questionnaire [55]

${ }^{\mathrm{d}}$ Measure Development Based on Normalization Process Theory [56]

Phase III: For the questionnaire survey in terms of the summative evaluation a participation of $N=130$ key stakeholders of local (primary) palliative care delivery from the practical, education, economic, and policy sphere, as well as representatives of patients and relatives is proposed based on content-related reflections taking the accumulated sample size of the prior subprojects into account.

\section{Methods of data analysis}

Phase I + III: Analysis of qualitative data (ethnographic field research, CIT, secondary analysis of interviews and focus group), as well as for the formative evaluation during the implementation phase (organizational ethnographic approach with individual and group interviews) will be guided by the methodology of Grounded Theory. For each qualitative data-subset (field notes, interviews, 
focus group), Strauss and Corbin's single coding paradigm [41] will be used to identify salient determinants and mechanisms of relevance to primary PC delivery in general practice. To ensure inter-subjective validity and reliability, qualitative data will be analyzed independently by the members of the junior research group and discussed within the team until consensus on core categories will be reached. Analysis of health insurance claims data and GPs' office software will follow the guidelines for best practice of secondary data analysis [42]. For quantitative data analysis univariate and bivariate descriptive methods as well multivariate methods (e.g. logistic regression or survival analysis [43, 44]) of empirical social research will be used. The findings from the different data sources within the theoretical phase will be triangulated to draw inferences on the structural, economic, and interactional mechanisms that either hamper or facilitate PC delivery in general practice.

Phase II: A characteristic feature of Participatory Action Research is community and practice partners' participation also in the phase of data analysis [45]. Mutual reflection, shared learning and co-construction of meaningful outcomes are key elements of this process; for this aim, pragmatic and comprehensible methods are recommendable such as thematic or content analysis, or the single coding paradigm. A stepwise approach to data analysis will be conducted in working groups composed of academic staff and representatives from the field [45]. Outcomes of the Nominal Group Technique employed during the consensus workshops will be analyzed using quantitative (descriptive comparison between ranks and weights of ideas and statements) and qualitative methods (combination of structured-thematic and formal qualitative content analysis) [46].

The Delphi study and the questionnaire survey will be analyzed using descriptive statistics (percentages, measure of central tendencies such as mean and median values, and measures of dispersion such as variance, interquartile ranges, and standard deviation). For the Delphi study, results of concluded survey rounds will be processed to provide feedback to the participants in the subsequent round [47]. If necessary, service development statements will be modified based on the experts' responses in order to inform the questionnaire for the next survey round and hereby improve the degree of consensus within the expert panel. For the development of the tailored intervention package, data from the different sources in the modelling phase will be integrated in accordance with the framework for the design of complex interventions [26] and the corresponding guidance for synthesizing and triangulating mixed methods data (48). Following the recommended phases of the mixed methods analysis process [48], a package of expedient interventions will be proposed and elaborated based on the data collected during the participatory process, will be translated into service development statements, and consented during the subsequent Delphi survey and consensus workshops.

Statistical analysis will be compared and contrasted with qualitative data on direct and indirect costs resulting from organizational ethnographic research including individual and group interviews using triangulation. Standardized patient-related outcomes such as Palliative Outcome Scale [38] or Quality of Dying and Death questionnaire [49] (Table 2) will be analyzed according to the instructions for scoring, analysis, and interpretation of responses indicated by the authors in the instruments' manual, on the respective website, or in key publications.

All qualitative analysis will be conducted using software for qualitative text analysis $\left(\mathrm{MAXQDA}^{\circ}\right)$. Quantitative data will be analyzed using IBM SPSS Statistics (Version 24) and R (Version 3.3.0).

\section{Expected results}

Following the principles of organizational health services research [26, 27] and implementation science [37, 50], significant results and knowledge gain of this project are expected at different stages of the research process and on different levels of changes in practice.

a) The expected outcome of the theoretical phase will be a salient program theory [26] on determinants of primary PC in general practice. This will include specific knowledge on barriers impeding routine embedding of PC provision in general practice and its consequences for patient care.

b) The modelling phase is expected to generate (a) a set of service development statements [34, 35] that will serve as guidance for the development of a tailored intervention package and that will be submitted to a consensus building process in order to substantiate feasibility and applicability of the proposed actions on a broader professional basis; and (b) an intervention package tailored to the German health care context that will enable GPs to provide PC to their patients according to their professional standards and to the best of the patient's needs and requirements. The intervention package will be designed to address the barriers identified in phase one and will include flexible modules that can be adapted to different local or regional conditions. The insights gained during this phase will deliver specific information on measurable actions to improve the conditions for GPs to provide high quality primary PC.

c) The expected outcome of the implementation and evaluation phase will be an evidence-based, pilottested intervention package and a national strategic action plan on the enhancement of primary PC 
delivery by GPs in Germany. This will comprise knowledge on its practicality, its impact on care and patient-relevant outcomes, as well as on suitable quality indicators for primary PC in general practice.

\section{Discussion}

In the meantime, the theoretical phase I of the project is partly completed. In the first sub-project, the organizational ethnographic field approach, a total of ten GPs, eleven GPs' assistants and nine professional caregivers were accompanied by a scientific co-worker of the research team in their daily work. The method of data collection was proven very suitable for answering the research question. It allowed observing and understanding the broad spectrum of GPs' and their assistants' daily work and gave valuable information on the routine of GPs' practices and the specific demands and financial background of delivering palliative care for GPs. By gaining comprehensive insights it has become possible to draw conclusions on barriers and facilitators to primary PC provision.

Second, the secondary analysis of qualitative data comprised 52 longitudinal interviews with 14 GPs carried out at up to four time points in six-monthly intervals. Additionally, three focus groups with GPs $(n=5)$, medical assistants $(n=6)$, and professional caregivers $(n=11)$ were considered. Analyzing this extensive data material allowed investigating the GPs' perspective on and actions in end-of-life care. The interviews particularly contributed to the understanding of GPs' discrimination and definition of patients in need of geriatric or palliative care.

Third, focused interviews with each four GPs, GPs' assistants or professional caregivers from palliative or nursing home care, patients, and relatives using the CIT [31, 32] were conducted. The method was very helpful to assess different perspectives of care provider and care recipients and to distinguish which care contexts are perceived successful and positive or inappropriate and negative. Nevertheless, for patients and relatives it was difficult to distinguish in their reporting between a positive and negative example and not to integrate and mix both positive and negative care events. This way of describing care situations was less complex for GPs and other care professionals.

The secondary analysis of health insurance claims data of the AOK - Die Gesundheitskasse für Niedersachsen (AOKN, statutory health insurance) and BARMER (statutory health insurance) foreseen for the fourth sub-project of phase I is still ongoing and will probably continue until the end of the second project year. Though good relations between the research team and the authorities of the health insurances were developed, the provision of data was delayed due to technical problems or heavy workload. The clarification of data protection and legal issues, the conclusion of contracts and data transfer took more time and required more resources of all engaged persons than considered in the study design during grant application.

Overall, this project has the potential to substantially contribute to the practical elaboration of enhanced approaches to primary PC service provision with evidencebased intervention models, in particular with respect to the enhancement of collaboration and networking. Significant benefits for patients and their relatives are expected from improved primary PC delivery and improved collaboration with PC specialists, such as earlier identification of patients in need of PC, better assessment and treatment of pain and other symptoms, advanced care planning, and avoidance of unwanted lifeprolonging treatments. But also benefits for healthcare professionals can be expected.

\section{Ethical issues}

The methodological approach of this project does not involve any direct interventions or exposures to patients. However, several elements of data collection, data analysis, and publication of results require careful attention. $\mathrm{PC}$ is a sensitive field of health care with particular challenges for research; severely ill and dying people are considered a particularly vulnerable group and data collection can be potentially burdensome for participants [51]. The legitimacy of involving patients and relatives in scientific research has therefore been subject to debate in terms of research ethics. Evidence from studies and systematic reviews on ethical issues of research in PC suggests that - a diligent and respectful approach provided - research is both ethically justifiable and also desirable [51, 52]. Based on this evidence, a conceptual framework for ethics and data protection was elaborated for this project, taking particular account of a reasonable balance between effort, costs, and potential burden for participants, and the expected knowledge gain. During data collection, the participants' health condition will be considered when choosing methods and settings of inquiry; care will be taken to keep periods of inquiry short.

The nature of ethnographic field research and PAR on the one hand bears ethical challenges such as problems of attaining informed consent; the power of interpretation; or dealing with secrets [53]. On the other hand, this type of research offers the opportunity of respectful interaction with all involved actors [51]. Consent and trust are dynamic and interactive concepts, and care will be taken to continuously sustain these throughout the research process by ensuring mutuality and creating an "ethical space" between researchers and partners in the field [54]. Research activities will be conducted in line with international ethics guidelines for ethnographic studies [55] and PAR [45], hereby assuring compliance with the principles of beneficence, non-maleficence, and 
protecting the autonomy, wellbeing, safety, and dignity. Since it will not be possible to attain individual informed consent from all participants - including patients communication and comprehension of information, and voluntary participation will be assured by creating the highest possible transparency, e.g. through posters and flyers in waiting rooms of general practices, or the researcher wearing a badge identifying him as such. Regular supervision will be provided for the researchers in the field. Ethical considerations regarding secondary analysis of qualitative data mainly include concerns about reusing data for a different purpose without having the explicit consent from participants [56]. This will not be applicable here since this study can be considered a follow-up of the original project; data collection referred to a similar context of practice, and the participating GPs consented that data may be used for scientific purposes in terms of developing an empirically grounded intervention that builds on the project's findings. In ethical and economic terms of undertaking research, secondary analysis will support careful use of already invested funding and resources for data collection, and avoid unnecessary burden on participants [30]. A data protection concept will ensure anonymity of individual persons by systematic anonymization and pseudonymization of collected data. A final version of the study protocol including a data protection plan was submitted for approval to the ethics committee of Hannover Medical School.

\section{Dissemination and implementation}

Engaging partners during the project in the process of implementation and dissemination of the research findings will be ensured by the research design that substantially builds on participatory and consensus building techniques. A key feature of these methods is the creation of ownership of the outcomes and hereby enhancing incorporation into practice and impact on healthcare. It is inherent to the principles of PAR that it involves participation from partners at all stages of the research process, including implementation and dissemination [45]. This will help identifying relevant audiences for the outcomes of this project, as well as suitable strategies and contexts for dissemination and implementation. Since the relevant actors regarding care practice, education, financing, laws and regulations, as well as policy decision making will be involved in the core developmental stages of the tailored intervention package, translation of the outcomes into targeted action will be promoted not only at the end of the project ("end of grant knowledge translation"), but already throughout its duration ("integrated knowledge translation") [45]. Ongoing benefit for the practice of primary PC provision is expected by reciprocal learning and mutual elaboration of strategies for improving action throughout the collaboration within the project. The expected product of this project, i.e. an evidence-based, pilot-tested intervention package and a national strategic action plan on the enhancement of primary PC provision by GPs in Germany, will be disseminated via diverse channels to ensure that all relevant audiences will be reached. Next to publication in scientific journals and presentation at (inter)national conferences, the following dissemination formats will be envisaged: executive summaries for health policy decision makers and health insurance funds stating the need and recommendations for action to improve conditions for primary PC provision in general practice; tools for practice, developed and consented during the modelling phase and refined during the implementation phase of the project; press information and personal stories illustrating the impact of adequate primary PC provision for the media; and position papers for professional associations in general practice and PC including recommendations for practice and for curriculum development. Formats of presentation and dissemination will be elaborated in collaboration with the partners in the field to ensure connectivity for different target audiences. Dissemination will be supported by the research institute's close links to health policy makers, professional boards and associations, health insurance funds, as well as national and international collaboration in PC and health services research.

\section{Abbreviations \\ AOKN: AOK - Die Gesundheitskasse für Niedersachsen; CIT: Critical Incident Technique; DEGAM: German Association of General Practice; DGP: German Association of Palliative Care; ELFOP: End of life care for frail older patients in family practice; GP: General practitioners; PAR: Participatory action research; PC: Palliative Care}

\section{Acknowledgements}

We thank Dr. PH Gabriele Müller-Mundt for supporting the grant application and providing data from ELFOP (BMBF-FK 01 GY 1120) for this research project. We thank Dr. Kathrin Matthias (palliative unit of the Hannover Medical School) for helpful remarks and supporting the recruitment of interview participants.

The permission of the AOKN and BARMER to work with the health insurance claims data is greatly acknowledged. In particular, we thank Dr. Jürgen Peter (AOKN), Dr. Sveja Eberhard (AOKN), and Dr. Ursula Marschall (BARMER) for supplying the data for this research project.

\section{Funding \\ This study is funded as a junior researcher group by the German Ministry of Education and Research within the program for enhancing infrastructures in health services research (Grant N01GY1610). The funding body does not have any influence on the design of the study and collection, analysis, and interpretation of data, or in writing the manuscript.}

\section{Availability of data and materials}

Qualitative data (e.g. transcriptions, notes, etc.) collected during study application are available from the first authors on reasonable request. Datasets from both health insurance funds generated and analyzed during the theoretical phase of this study are not publicly available due to regulations of data privacy protection. 


\section{Authors' contributions}

SJ had the initial idea for this project and developed the original study plan. HE and FT made substantial contributions to conception and design of the final study protocol; they equally contributed to writing and editing the manuscript. SS, as the leader of the junior research group, made significant contributions to the discussion section, and provided supervision and professional advice on writing and editing the manuscript. NSch supported the quality of the manuscript by revising it critically for important intellectual content, based on their longstanding expertise in the social sciences, in public health research, and in primary palliative care. All authors have given approval to the final version of the manuscript.

\section{Ethics approval and consent to participate}

Ethics approval was granted by the ethics committee of Hannover Medical School on 14th February 2017 (Registration N 7260).

\section{Consent for publication}

Not applicable

\section{Competing interests}

The authors declare that they have no competing interests.

\section{Publisher's Note}

Springer Nature remains neutral with regard to jurisdictional claims in published maps and institutional affiliations.

\section{Author details}

'Institute for General Practice, Hannover Medical School, Carl-Neuberg-Straße 1, 30625 Hanover, Germany. ${ }^{2}$ Cologne Center for Ethics, Rights, Economics and Social Sciences of Health, University of Cologne, Universitätsstraße 91, 50931 Cologne, Germany.

Received: 19 December 2017 Accepted: 22 January 2018 Published online: 30 January 2018

\section{References}

1. Sepulveda C, Marlin A, Yoshida T, Ullrich A. Palliative Care: the World Health Organization's global perspective. J Pain Symptom Manag. 2002;24(2):91-6.

2. Gott M, Seymour J, Ingleton C, Gardiner C, Bellamy G. That's part of everybody's job': the perspectives of health care staff in England and New Zealand on the meaning and remit of palliative care. Palliat Med. 2012;26(3):232-41.

3. Strukturen und regionale Unterschiede in der Hospiz-und Palliatiwersorgung [Internet]. Bertelsmann-Stiftung. 2015. https:/www.bertelsmann-stiftung.de/ fileadmin/files/BSt/Publikationen/GrauePublikationen/Studie_W_FCG_ Versorgungsstrukturen-palliativ.pdf. Accessed 17 Dec 2017.

4. Malpas PJ, Mitchell K. "doctors Shouldn't underestimate the power that they have": NZ doctors on the Care of the Dying Patient. Am J Hosp Palliat Care. 2017:34(4):301-7.

5. Kratel U. Fortschritte in der ambulanten Palliative Care-Versorgung in Deutschland - Eine Bestandsaufnahme. Dtsch Z Onkol. 2014;46(01):8-15.

6. Gagyor I, Luthke A, Jansky M, Chenot JF. End Of life care in general practice: results of an observational survey with general practitioners. Schmerz. 2013; 27(3):289-95.

7. Australian Government. Australian institute of health and welfare. Service provider organisation: level of palliative care service 2007. http://meteor. aihw.gov.au/content/index.phtml/itemld/334508. Accessed 19 Dec 2017.

8. De Lima L, Bennett MI, Murray SA, Hudson P, Doyle D, Bruera E, et al. International Association for Hospice and Palliative Care (IAHPC) list of essential practices in palliative care. J Pain Palliat Care Pharmacother. 2012; 26(2):118-22.

9. Radbruch L, Payne S. White Paper on standards and norms for hospice and palliative care in Europe: part 1. Eur J Palliat Care. 2009;16(6):278-89.

10. Quill TE, Abernethy AP. Generalist plus specialist palliative care-creating a more sustainable model. New Engl J Med. 2013;368(13):1173-5.

11. Thomas K, Free A. The gold standards framework is pivotal to palliative care. Guidel Pract. 2006;9:29-39.

12. Shaw KL, Clifford C, Thomas K, Meehan H. Review: improving end-of-life care: a critical review of the gold standards framework in primary care. Palliat Med. 2010;24(3):317-29.

13. Murray SA, Firth A, Schneider N, Van den Eynden B, Gomez-Batiste X, Brogaard T, et al. Promoting palliative care in the community: production of the primary palliative care toolkit by the European Association of Palliative Care Taskforce in primary palliative care. Palliat Med. 2015;29(2):101-11.

14. Afshar K, Geiger K, Müller-Mundt G, Bleidorn J, Schneider N. Hausärztliche Palliativversorgung bei nichtonkologischen Patienten. Schmerz. 2015;29(6): 604-15.

15. Mitchell GK, Reymond EJ, BP MG. Palliative care: promoting general practice participation. Med J Aust. 2004;180(5):207-8.

16. Deutsche Gesellschaft für Palliativmedizin e. V. S3-Leitlinie Palliativmedizin für Patienten mit einer nicht heilbaren Krebserkrankung, Langversion 1.1. Leitlinienprogramm Onkolgie der Arbeitsgemeinschaft der Wissenschaftlichen Medizinischen Fachgesellschaften e. V. (AWMF), Deutsche Krebsgesellschaft e. V. (DKG) und Deutsche Krebshilfe (DKH), editors. 2015. http://www.leitlinienprogramm-onkologie.de/fileadmin/ user_upload/Downloads/Leitlinien/Palliativmedizin/LL_Palliativmedizin_ Langversion_1_1.pdf. Accessed 17 Dec 2017.

17. Deutsche Gesellschaft für Palliativmedizin e. V. Deutscher Hospiz- und PalliativVerband e. V., Bundesärztekammer. Charta zur Betreuung schwerstkranker und sterbender Menschen in Deutschland. 2016.

18. Behmann M, Junger S, Radbruch L, Schneider N. Public health actions to improve palliative care in Germany: results of a three-round Delphi study. Health Policy. 2012;106(3):303-12.

19. Bundesministerium für Gesundheit. Gesetz zur Verbesserung der Hospizund Palliativversorgung in Deutschland (Hospiz- und Palliativgesetz - HPG) vom 1. Dezember 2015. Bundesgesetzesblatt2015. p. 2114-9.

20. Schneider N. Rubrik Wissen: Das Hospiz- und Palliativgesetz. Bedeutung für die hausärztliche Praxis. Pflegen: palliativ. 2016;29:36-7.

21. Burt J, Shipman C, Addington-Hall J, White P. Nursing the dying within a generalist caseload: a focus group study of district nurses. Int I Nurs Stud. 2008;45(10):1470-8.

22. Victorian Government. Department of health. Strengthening palliative care: Policy and strategic directions 2011-2015. https://www2.health.vic.gov.au/ about/publications/policiesandguidelines/strengthening-palliative-carepolicy-strategic-directions-2011-2015. Accessed 17 Dec 2017.

23. Koch K, Miksch A, Schurmann C, Joos S, Sawicki PT. The German health care system in international comparison: the primary care physicians' perspective. Dtsch Arztebl Int. 2011;108(15):255-61.

24. Dahlhaus A, Vanneman N, Siebenhofer A, Brosche M, Guethlin C. Involvement of general practitioners in palliative cancer care: a qualitative study. Support Care Cancer. 2013;21(12):3293-300.

25. Hermann K, Engeser P, Szecsenyi J, Miksch A. Palliative patients cared for at home by PAMINO-trained and other GPS - health-related quality of life as measured by QLQ-C15-PAL and POS. BMC Palliat Care. 2012;11:13.

26. Campbell M, Fitzpatrick R, Haines A, Kinmonth AL, Sandercock P, Spiegelhalter $D$, et al. Framework for design and evaluation of complex interventions to improve health. BMJ (Clin Res ed). 2000;321(7262):694-6.

27. Pfaff H, Albert US, Bornemann R, Ernstmann N, Gostomzyk J, Gottwik MG, et al. methods for organisational health services research. Gesundheitswesen. 2009;71(11):777-90.

28. Willis GB. Cognitive interviewing: a "how to" guide. In: Caspar RA, Lessler JT, Willis $\mathrm{GB}$, editors. Reducing survey error through research on the cognitive and decision processes in surveys. Meeting of the American Statistical Association. Research Triangle Institute: North Carolina, United States; 1999.

29. Emerson RM, Fretz Rl, Shaw LL, editors. Writing ethnographic fieldnotes. 1st ed. Chicago: University of Chicago Press; 1995.

30. Huschka D, Knoblauch H, Oellers C, Solga H, editors. Forschungsinfrastrukturen für die qualitative Sozialforschung. 1st ed. Berlin: Scivero; 2013

31. Kemppainen JK. The critical incident technique and nursing care quality research. J Adv Nurs. 2000;32(5):1264-71.

32. Mallak LA, Lyth DM, Olson SD, Ulshafer SM, Sardone FJ. Diagnosing culture in health-care organizations using critical incidents. Int Journal Health Care Qual Assur. 2003;16(4):180-90.

33. Froggatt $\mathrm{K}$, Hockley J. Action research in palliative care: defining an evaluation methodology. Palliat Med. 2011;25(8):782-7.

34. Mason B, Epiphaniou E, Nanton V, Donaldson A, Shipman C, Daveson BA, et al. Coordination of care for individuals with advanced progressive conditions: a multi-site ethnographic and serial interview study. Br J Gen Pract. 2013;63(613):e580-8.

35. Mason B, Donaldson A, Epiphaniou E, Nanton V, Shipman C, Daveson B, et al. Coordination of care for people at risk of dying in the next 12 months: a multi-site prospective study and consensus seeking exercise. London: 
National Institute for Health Research Service Delivery and Organisation Programme. 2013:1-194.

36. Daveson BA, de Wolf-Linder S, Witt J, Newson K, Morris C, Higginson IJ, et al. Results of a transparent expert consultation on patient and public involvement in palliative care research. Palliat Med. 2015;29(10):939-49.

37. May C. Towards a general theory of implementation. Implement Sci. 2013;8:18.

38. Bausewein C, Fegg M, Radbruch L, Nauck F, von Mackensen S, Borasio GD, et al. Validation and clinical application of the german version of the palliative care outcome scale. J Pain Symptom Manag. 2005;30(1):51-62.

39. Fusch PI, Ness LR. Are We There yet? Data saturation in qualitative research, Qual Rep. 2015;20(9):1408-16.

40. Palinkas LA, Horwitz SM, Green CA, Wisdom JP, Duan N, Hoagwood K. Purposeful sampling for qualitative data collection and analysis in mixed method implementation research. Admin Pol Ment Health. 2015;42(5):533-44.

41. Corbin J, Strauss A. Basics of qualitative research: techniques and procedures for developing grounded theory: Sage Publications; 2015

42. Swart E, Gothe H, Geyer S, Jaunzeme J, Maier B, Grobe TG, et al. Gute Praxis Sekundärdatenanalyse (GPS): Leitlinien und Empfehlungen. Gesundheitswesen. 2015;77(02):120-6.

43. Backhaus K, Erichson B, Plinke W, Weiber R. Multivariate Analysemethoden: eine anwendungsorientierte Einführung. 14th ed. Springer Gabler: SpringerVerlag Berlin Heidelberg; 2015.

44. Bühl A. SPSS 18 (ehemals PASW): Einführung in die moderne Datenanalyse: Tata McGraw-Hill. Education. 2010;

45. von Unger H. Partizipative Forschung: Einführung in die Forschungspraxis. Springer VS: Wiesbaden; 2014.

46. Gallagher M, Hares T, Spencer J, Bradshaw C, Webb I. The nominal group technique: a research tool for general practice? Fam Pract. 1993;10(1):76-81.

47. Häder M. Delphi-Befragungen: Ein Arbeitsbuch. 3rd ed. Springer VS: Wiesbaden; 2014.

48. Farquhar MC, Ewing G, Booth S. Using mixed methods to develop and evaluate complex interventions in palliative care research. Palliat Med. 2011; 25(8):748-57.

49. Heckel M, Bussmann S, Stiel S, Weber M, Ostgathe C. Validation of the German version of the quality of dying and death questionnaire for informal caregivers (OODD-D-Ang). J Pain Symptom Manag. 2015:50(3):402-13.

50. Finch TL, Mair FS, O'Donnell C, Murray E, May CR. From theory to 'measurement' in complex interventions: methodological lessons from the development of an e-health normalisation instrument. BMC Med Res Methodol. 2012;12:69.

51. Gysels MH, Evans C, Higginson IJ. Patient, caregiver, health professional and researcher views and experiences of participating in research at the end of life: a critical interpretive synthesis of the literature. BMC Med Res Methodol. 2012:12:123.

52. PR CMA, de Vries K. Can qualitative interviews have benefits for participants in end-of-life care research? Eur J Palliat Care. 2016;23(5):227-31.

53. Li J. Ethical Challenges in participant observation: a reflection on ethnographic fieldwork. Qual Rep. 2008;13(1):100-15.

54. Brazil K. Issues of diversity: participatory action research with indigenous peoples. In: Hockley J, Froggatt K, Heimerl K, editors. Participatory research in palliative care: actions and reflections. United Kingdom: Oxford University Press; 2013.

55. Ethical guidelines for good research practice. 2011. http://www.theasa.org/ downloads/ASA\%20ethics\%20guidelines\%202011.pdf. Accessed 17 Dec 2017.

56. Recycling the evidence: Different approaches to the reanalysis of gerontological data. 2005. http://nbn-resolving.de/urn:nbn:de:0114-fas0501424. Accessed 17 Dec 2017.

\section{Submit your next manuscript to BioMed Central and we will help you at every step:}

- We accept pre-submission inquiries

- Our selector tool helps you to find the most relevant journal

- We provide round the clock customer support

- Convenient online submission

- Thorough peer review

- Inclusion in PubMed and all major indexing services

- Maximum visibility for your research

Submit your manuscript at www.biomedcentral.com/submit 